\title{
Research on Cultural Ecology of Chinese Folk Industrial Arts in Eastern Hubei Province
}

\author{
Jun Sun \\ Huanggang Normal University \\ Huanggang, China
}

\begin{abstract}
Eastern Hubei Province has a long cultural history, rich and colorful. It is the foundation for development of Chinese folk industrial arts, providing ceaseless spiritual nutriment and fresh blood for development of folk art. Since different cultural ecological factors influence folk art in different ways and on different layers, eastern Hubei Province's cultural ecological system falls into two subecological systems, namely traditional culture (Chinese traditional culture) and regional culture(local culture of eastern Hubei Province). Ecological factors of traditional culture and regional culture influence and constrain each other, keeping a dynamic balance.
\end{abstract}

Keywords-cultural ecology; industrial art; Eastern Hubei Province

\section{INTRODUCTION}

In the endless agricultural society, accompanied by great quantities of laborers' life, production and folk customs, Chinese folk industrial arts comes into being, develops and continues. Its existence beautifies goods, life and living environment. Like a folk song, it gathers large quantities of laborers' passion for life, love for their homeland, expectations of happiness and pursuit of a good life, and contains laborers' psychological quality and spiritual connotation, reflecting their plain aesthetic concept. In other words, Chinese folk industrial arts is art of life, which comes into being in specific folk culture and exists in specific cultural ecological circumstances.[1] Seeing through China's civilization history, there is no fracture in China's long history of culture and tradition. Therefore, Chinese folk industrial arts contains extremely rich and antiquated historical cultural relics with strong traces of agricultural society. Chinese folk industrial arts is of group culture type, accumulated, inherited and innovated by hundreds of millions of labor communities in the long history. It melts into national groups' social life, like their basic necessities of life, festival custom and belief and taboos. It is the parent of Chinese nation's cultural art with distinguished national and regional features, which are important symbols of cultural ecology. Seeing from the whole of national culture, the ecology here includes the whole nation's philosophical concept, cultural awareness, emotion, temperament and psychological quality. In terms of this aspect, compared with

Fund program: Major project of humanities and social sciences of Education Department of Hubei Province-Research on Chinese folk industrial arts and cultural ecology of eastern Hubei Province (17D082). its own artistic value, it is more valuable to research on cultural ecology of Chinese folk industrial arts.

\section{TRADITIONAL CULTURE OF EASTERN HUBEI}

PROVINCE--HOMELAND PSYCHOLOGY OF AGRICULTURAL CIVILIZATION

Eastern Hubei Province is on the borders between the two kingdoms $\mathrm{Wu}$ and $\mathrm{Chu}$, adjacent to Henan, Anhui and Jiangxi, three provinces in total. In its northward lies Dabie Mountain and in its southward lies the Yangtze River. It has four distinctive seasons with abundant rain, a mild climate and independent cultural geography since ancient times. Since Song Dynasty, especially Ming Dynasty, developed agricultural culture tradition has been formed here. People's cultural psychology is established through concrete production and life practice. Eastern Hubei Province has a relatively comfortable climate, enabling its typical selfsubsistence peasant economy to develop to an extreme. The peasants there rely on themselves to grow and grind grains, grow cotton, wave cloth, grow seeds, extract oil, grow vegetables to eat, cut firewood to burn, brew vinegar for personal use and so on. They rarely exchange products. Even if there is exchange, it is done in a small range of dozens of miles around. Although they are not rich, depending on being accordant with the rhyme of nature and traditional agricultural skills of intensive cultivation, as long as they work industriously and there is good weather, they can have enough to eat and wear, enabling their family to avoid cold and hunger. There is no way for agriculture to deviate from land. It is exactly because of this kind of strong bonding that people in eastern Hubei Province miss their homeland a lot and have deep love for their homeland, making it hard to leave their homeland. Although the number of peasants grows continuously, opening up wasteland keeps pace with it, gradually expanding from a point as the center. From their home to the village, they take root in their homeland and it is extremely difficult for them to leave their homeland. Unless there are natural and man-made disasters, otherwise they won't go far away from their homeland. People in eastern Hubei Province naturally form the cultural tradition and psychological pattern of keeping the fate of life, promised land, emphasizing agriculture and being down-to-earth, which contains a strong rational sense and utility color. 


\section{Regional Culture of EAstern Hubei}

PROVINCE-RURAL FESTIVAL AND FOLK BELIEF

All regional culture develops on the basis of traditional culture. Due to differences in natural ecological environment, various types of regional culture come into being. In regional culture, people's living habit, time and seasons, life rituals, content of folk belief custom and habits regulate the rich connotation of Chinese folk industrial arts and their dynamic cultural pattern. Regional difference is the most important reason for uniqueness of Chinese folk industrial arts.

\section{A. Abundant Traditional Festivals}

There are abundant festivals in eastern Hubei Province, like Spring Festival, Lantern Festival, Tomb-sweeping Day, Dragon Boat Festival, Hungry Ghost Festival, Mid-autumn Festival, Double Ninth Festival, Laba Festival and so on. Spring Festival is commonly known as "Guo Nian", the grandest folk festival, during which people do shopping, send "the god of kitchen" to heaven, clean the house, dust, make steamed buns, fry vegetable, paste spring poems, set off firecrackers, and eat dumplings, with people singing and dancing joyously. The Lantern Festival is on the fifteenth day of the first lunar month, when people make flower oil lamps and festive lanterns, shoot off fireworks, play dragon lanterns, walk on stilts, do the row-boat dance and throw grass torches, an extremely lively scene. There is an old saying of "Dragon Heads-raising Day" on the 2nd day of the 2nd lunar month when people pray for good weather and a golden harvest. On Tomb-sweeping Day, willow branches are inserted under the roof or beside the door and people have boiled eggs for breakfast. "Dragon Boat Festival" is on the 5th day of the 5th lunar month when mugwort branches are inserted under the roof with red dates and sticky rice zongzi and deep-fry sugar cake as its special food. "Midautumn Festival" is on the 15th day of the 8th lunar month when every family prepares moon cakes, fruits, food and drink, entertaining at a banquet and admiring the full moon. "Double Ninth Day" is on the 9th day of the 9th lunar month with the custom of showing filial piety to the elders and ascending a height to enjoy autumn. "Laba Festival" is on the 8th day of the 12th lunar month when every family get up early to boil "rice porridge with nuts and dried fruit", sacrifice ancestors and gods of heaven and earth, and pray for a harvest and an auspicious omen.

\section{B. Folk Belief Custom}

Eastern Hubei Province has a traditional rain agriculture society. Although there are water conservancy projects in history, precipitation is still an important factor influencing its agricultural development. Seeing from the folk adage of "Spring rain is as precious as oil while a lot of it makes peasant worry", "Streetful spring rain indicates a good harvest of wheat" and "Continuous rain in June makes gold appear everywhere", we can know the importance of rain to agriculture. A good weather is the ideal of peasants, therefore correspondingly they worship rain. There is a different rain god for each region, so does the way to pray for rain. In eastern Hubei Province, there is a custom belief believing that the Dragon King dominates rain, shine, drought and flood which are closely related to agricultural production. Therefore, in many places of eastern Hubei Province, there are activities to pray for rain or shine mainly conducted by worshipping the Dragon King. For example, there are activities to pray for rain in Hong'an. Young boys and girls are organized and an elder leads the villagers in gathering flour and oil to fry dough sticks or make steamed tiger-shaped buns as sacrificial offerings. Then the activity of "roasting stones and bathing lion babies" begins. In Macheng, when there is excessive rain without sunshine, people will make a paper woman and paste it on the broom, which is called "sweeping the goddess". Local people hang the broom in the courtyard, believing "sweeping the goddess" can clear away all the clouds in the sky and it will clear up. In eastern Hubei Province, there are two mandarin ducks tumbling merrily about in the water or playing merrily with lotus, phoenixes playing with peony, lotus growing among lotus leaves, rich peony, seedy pomegranate, fish playing with lotus(usually appearing on bellyband, pillow sides, insole, curtain, letter rack, handkerchief and scissor-cut), dragons flying and phoenixes dancing, kylin sending decedents, stripped pomegranate containing a lot of seeds, lotus pod and sweet scented osmanthus, baby sitting on the lotus, scorpion turning into a baby, lion turning into a baby and so on in industrial art, like straw plaited article, New Year pictures, scissor-cut, fabrics and so on, demonstrate people's hope for continuation and passing on of their clan and surname, expansion of family power and increase of labor force. Unique natural ecological environment brings about the unique psychology, cultural experience, aesthetic interest and life concept of people in eastern Hubei Province, making up the profound background of production and cultural ecology of Chinese folk industrial arts of people in eastern Hubei Province.

\section{Meticulous and Complicated Life Etiquette}

As to local etiquette and custom, there is mainly wedding, birth, celebrating birthday, and funeral. Marriage custom is the most complicated. The matchmaker holds a post containing the male's birth date and the eight characters of a horoscope and goes to the female's home, known as "making a proposal". Permitted by the female, the male's side can give "betrothal gifts" to the female's side. Then, both sides choose a lucky day for marriage, known as "choosing an auspicious day". The day before getting married, the bridegroom's side sends a bridal sedan chair to the bride's home, known as "accepting the sedan". The bride's relatives and friends go to the bride's home to present gifts, known as "wedding presents sent to the bride's family". In the wee hours of the day when they get married, the bride puts on the red clothes sent by the bridegroom's side, known as "changing hair style". When the sedan arrives at the bridegroom's house, the bridegroom needs to "worship the sedan god" and pick up the bride. Then, the bridegroom's elder brothers pour red dates, peanut, walnut, chestnut, wheat bran and grass stick onto the bride's head, known as "casting towards bed curtain". The bridegroom and bride pay tributes to each other, known as "performing the formal wedding ceremony". Placing red dates and chestnut under bedding of the wedding bed indicates "giving birth to a son as soon as 
possible". Next day, the bridegroom and the bride worship the bridegroom's ancestral grave, known as "identifying ancestors". On the third day of the wedding, the new couple goes to the bride's home to greet her parents, known as "the return of a bride to her mother's home". As to birth etiquette and custom, there is child delivery hastening, announcing good news, sending rice and flour and the return to the female's mother's home upon a baby's completion of its first month of life. In ancient times, the birthday of a man reaching 60 can be called "Shou". In order to celebrate the 66th, 71st and 73rd birthday of an old man or woman, the house is decorated with lanterns and streamers, and there is a mourning hall, fruit offerings and burning candles and incense. The star of longevity sits in the main house and enjoys successive worship from his/her children, relatives and friends, quite a grand scene. Passing away of an old person is called "perishment". The funeral arrangement is also called "funeral affairs". As to its etiquette, there is burying a parent, giving an obituary notice, encoffining, standing as guards at the bier, carrying a coffin to the cemetery, burying the dead, adding soil to the grave and observing mourning for one's parent. As to its custom, there is wearing mourning dress, making paper horses, paper people, bridal sedan chairs, and colorful steamers, burning joss paper, sending travelling expenses(or "sending broth"), throwing the "old basin" and so on.

\section{Wide Spread of Folk-Custom Literature and Art}

As to folk dance in eastern Hubei Province, the most popular ones are flower-drum dance, lion dance and dragon lantern dance. Secondarily, there is bamboo hobbyhorse, land boat, festooned vehicle dance and stilts. Flower-drum dance is also called grand flower-drum stage walking, which is originally a basic play of folk flower-drum play with less singing and more dancing. Lion dance imitates various types of movement of a lion and integrates drama, dance, acrobatics and game into a whole, affording food for thought. Dragon lantern consists of nine sections respectively supported by wooden sticks, like dragon head, dragon body, and dragon tail and so on. During the performance, there is accompanying playing of suona horn and gong and drum. There is a person holding a bead to introduce the play in front of the dragon. People scramble for the bead at dragon head while the dragon body and dragon tail and other sections dance forward with the swaying of dragon head. In terms of bamboo horse, bamboo split is bundled to form the skeleton of a horse, gauze is used to cover the skeleton and scissor-cut horse hair is stuck to its external surface. Horse head is mobile. During a performance, the performer ties the horse body to his/her waist and uses hands to control the horse head to perform to the rhyme of music and gong and drum. Body of a land boat is made by bamboo and cloth and attached to the female dancer's waist. The gesture of sailing a boat is made in moving forward with a helmsman punting alongside. The performance goes along with local folk tunes. As to festooned vehicle dance, bamboo sticks are bundled to form a wheelbarrow with a covering above and flowers in various colors all around. The handlebar is tied to the female dancer's waist. There is a colorful circle around the vehicle with a "little boy" pulling in front of the vehicle and an "old dad" pushing behind the vehicle. These three performers coordinate to imitate a vehicle's moving forward, retreating, left and right turn, ascending and descending a slope, falling into a low-lying area and turnover, lively, vivacious and funny. As to stilts performance, a tall wooden leg is tied to either of the performer's legs. The performer plays the role of the character in drama with bamboo chips in hands to knock out rhythm along with the music of gong and drum. Chinese shadow puppetry has a long history here and shadow play artists usually go to other villages to make performances. Shadow play is mostly conducted in the evening, during which artists operate figures and animals made from donkey skin to perform behind the curtain with lighting of oil lamp. Shadow figures appear on the curtain with vivid gestures, attractive and full of dense local flavor.

\section{INFLUENCE OF EASTERN HUBEI PROVINCE'S}

\section{CULTURAL ECOLOGY ON CHINESE FOLK INDUSTRIAL ARTS}

“In human's spiritual practical activity field, aesthetic value creation of nation ecology is demonstrate through the form of art" [2]. Some ecological factors in eastern Hubei Province's natural environment directly influence the production of Chinese folk industrial arts. Since natural environment is damaged, changes take place in nature and texture of these materials, influencing handicraft production. Damage to environment also brings changes to folk artists' creation space. The original spring with birds singing and scented flowers becomes quiet, the nature is no longer the origin of inspiration for people and artistic production turns into indoor assembly line work. Seeing from the demand of material life, developed technology is able to provide all necessary living goods for people. Advanced and cool electronic tools replace the clay tiger and cloth tiger in children's hands, top grade and fashionable costume replaces the time-consuming and "outmoded" embroidery, star posters replace the scissor-cut on the window, presswork replaces New Year pictures made by hand, security door replaces stone lions protecting the household, and masked ball replaces facial masks. The changes here are inexorable results of social development, because advanced science and technology not only lower down living costs, but also bring a lot of convenience to people. Therefore, Chinese folk industrial arts with utility functions lose the reason for existence. Without consumers and producers, folk artists are reluctant to spend time making handiwork, leading to the loss of folk manual skills.

Seeing from the perspective of spiritual consumption, folk art's spiritual connotation itself originates from utilitarian need of life. When the society develops to a certain level, this kind of utilitarian need fades out gradually, especially that advanced science and technology makes people believe human is the master of the Earth. Fade-out dependence on spiritual world definitely will make Chinese folk industrial arts similar to "a walking corpse and running flesh", only leaving colors, modeling and ornamentation with regional features and losing its true connotation. Therefore, modern people's aesthetics on folk artwork is not mainly about "kindness" conforming to the purpose and artwork is mostly used as decorations in life. 


\section{CONCLUSION}

As a part of folk traditional culture, Chinese folk industrial arts contains deep historical memory and connotation. The reason why Chinese folk industry arts of eastern Hubei Province shows unique artistic charm is closely related to the ecological environment it lives on. Chinese folk industrial arts is the product of certain cultural environment at the mercy of natural environment. Eastern Hubei Province's natural ecological elements, traditional cultural ecological elements(agricultural culture and Confucian-rationality) and regional cultural ecological elements(life style, local customs and practices and folk belief) influence and constrain each other, forming a comprehensive, multidimensional and complicated relation.

Great changes take place in people's life style, folk belief customs become less and Chinese folk industrial arts losses its original existence space. Effective protection of Chinese folk industrial arts can't only be limited to display in museums. Instead, dynamic protection should be provided according to its nature of dynamic culture. Besides protection, folk art needs to search for new ways from its own law of development.

\section{REFERENCES}

[1] Sun Xia. Qingdao Folk Art Research in Light of Cultural Ecology [D]. Qingdao: Qingdao University of Science and Technology, 2010.

[2] Huang Bingsheng, Yuan Dingsheng. Ethnic Ecological Aesthetics [M]. Beijing: Nationalities Publishing House, 2004. 276. 